RASĀYAN J. Chem.

Vol. 13 | No. 1 |230 - 239| January - March | 2020 ISSN: 0974-1496 | e-ISSN: 0976-0083 | CODEN: RJCABP

\title{
Mangifera odorata GRIFF SEED EXTRACT AS CORROSION INHIBITOR OF MILD STEEL IN HYDROCHLORIC ACID MEDIUM
}

\author{
Y. Stiadi*, Rahmayeni, L. Rahmawati, M. Efdi, H. Aziz and Emriadi \\ Department of Chemistry, Faculty of Mathematics and Natural Sciences, Andalas University, \\ Padang, 25163, Indonesia \\ *E-mail: yenistiadi@sci.unand.ac.id
}

\begin{abstract}
Mangifera odorata Griff seed extract as a corrosion inhibitor of mild steel in 1M hydrochloric acid solution was investigated by weight loss, potentiodynamic polarization, and scanning electron microscopy methods. The results showed that the extract was able to inhibit the corrosion of mild steel with an inhibition efficiency of more than $90 \%$ at $8 \mathrm{~g} / \mathrm{L}$ Mangifera odorata Griff seed extract in $1 \mathrm{M}$ hydrochloric acid solution. The inhibition efficiency was found to be increased with increasing the extract concentration and decreased with increasing temperature. The adsorption of Mangifera odorata Griff seed extract on the mild steel surface follows the Langmuir adsorption isotherm and behaves as a mixed type inhibitor. The value of the highest inhibition efficiency of $91.78 \%$ was obtained by weight loss and $94.55 \%$ by potentiodynamic polarization method at MOSE concentration of $8 \mathrm{~g} / \mathrm{L}$ and the immersion temperature of $30^{\circ} \mathrm{C}$. Thermodynamic parameter values from the adsorption process indicate that the extracts can function as inhibitors due to it can increase the activation energy of mild steel dissolution.

Keywords: Mild Steel, Mangifera odorata Griff, Corrosion Inhibitor, Potentiodynamic Polarization.
\end{abstract}

ORASĀYAN. All rights reserved

\section{INTRODUCTION}

Acid solutions are commonly used in industrial fields such as industrial acid cleaning, chemical, electrochemical etching, acid descaling, cooling systems, and oil well acidizing. Among some acidic media used in industry, hydrochloric acid $(\mathrm{HCl})$ is one of more economical and efficient compared to other mineral acids. ${ }^{1-9}$ Corrosion inhibitors are generally used in several processes to prevent the oxidation of iron and iron alloys. However, some of these corrosion inhibitors are very disturbing to humans and the environment because of the toxicity of several inhibitors. Recently, many types of research were aimed to find an eco-friendly corrosion inhibitor. Most of the inhibitors were obtained from the natural product are biodegradable, non-toxic, and cheaper. ${ }^{4,6-8}$ It had been reported in the previous studies that the extracts of Toona sinensis, Lawsonia inermis, Aloe vera leaves, Theobroma cacao peels, and Flacourtia jangomas plant can inhibit the corrosion of the metal in an acidic environment. ${ }^{10-14}$

Mangifera odorata Griff is one type of fruit that is widely available in Indonesia. This fruit contains secondary metabolites that are rich in heteroatom groups that have free electron pairs so that they have the potential as a steel corrosion inhibitor. ${ }^{15}$ Various compounds containing nitrogen, oxygen or sulfur with conjugated systems can be used as corrosion inhibitors through adsorption of molecules on the metal surface to form a barrier layer to overcome the attack of corrosive substances. ${ }^{7,16}$

In this study, Mangifera odorata Griff seed extract (MOSE) was used to inhibit mild steel corrosion in hydrochloric acid medium. The effects of MOSE on corrosion inhibition of mild steel were investigated using the weight loss and electrochemical method. The surface of mild steel before and after corrosion was analyzed by scanning electron microscopy (SEM) and Fourier transform infrared (FTIR) analysis.

\section{EXPERIMENTAL}

\section{Material}

The materials used in this work were the seed of Mangifera ododrata Griff, mild plate steel, hydrochloric acid 37\% (Merck), methanol 95\%, distilled water, acetone, filter paper, and chloroform. The weight loss, Rasayan J. Chem., 13(1), 230-239(2020)

http://dx.doi.org/10.31788/RJC.2020.1315325

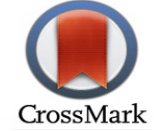


RASĀYAN J. Chem.

Vol. 13 | No. 1 |230 - 239| January - March | 2020

electrochemical methods, Fourier transform infrared (FTIR) and scanning electron microscope (SEM) was used to measure and determine the extent of the Mangifera odorata Griff seed extract (MOSE) can function as a mild steel corrosion inhibitor.

\section{General Procedure}

\section{Preparation of Mild Steel Specimens}

Specimens used for measurement were the mild steel sheets with composition (wt. \%) as follows:

C: 0.189, Mn: 0.141, P: 0.0149, Si: 0.0715, Ni: 0.001, Se: 0.019, Cr: 0.0018, and balance Fe. Mild steel sheets were mechanically cut to get a variety of different coupons, and each of the sheets has size is about $3.0 \times 2.0 \times 0.1 \mathrm{~cm}$. The sheets were given a small hole for the hanging thread. Each coupon is scraped off with emery paper and then rinsed with ethanol, dipped in acetone, and allowed to dry before storing it in a desiccator.

\section{Preparation of Seed Extract}

The seed of Mangifera odorata Griff was dried and ground to make powder. About $250 \mathrm{~g}$ of powder was macerated in $750 \mathrm{~mL}$ of methanol for 4 days. The maceration results were filtered and the filtrate was evaporated with a rotary evaporator. The concentrated extract of this seed was weighed $2 \mathrm{~g}$ and then diluted into a $100 \mathrm{~mL}$ measuring flask to obtain a concentration of $20 \mathrm{gL}^{-1}$. This result was used as a stock solution.

\section{Phytochemical Test of Seed}

Phytochemical tests of Mangifera odorata Griff seed extract were carried out using the methods that were commonly used in the previous work ${ }^{16}$. The extract was screened to determine flavonoids, phenolic, steroids, saponin, triterpenoid, and alkaloids compounds.

\section{Weight loss Method}

Coupon of mild steel was immersed in $50 \mathrm{~mL}$ of a corrosive medium of $1 \mathrm{M}$ hydrochloric acid solution in the present and without MOSE with a variety of concentrations. Variations of temperature were conducted at $30,40,50$, and $60^{\circ} \mathrm{C}$ for $7 \mathrm{~h}$ using a water bath. After that, the mild steel was cleaned with a brush, rinsed, and dried in an oven. Furthermore, the mild steel was weighed. By using the weight loss data, the corrosion rate $(C R)$ and inhibition efficiency $(I E)$ was calculated through the following equations;

$$
C R=\frac{\mathrm{m}_{1}-\mathrm{m}_{2}}{\mathrm{Axt}}
$$

and,

$$
I E \%=\frac{\mathrm{CR}_{1}-\mathrm{CR}_{2}}{\mathrm{CR}_{1}} \times 100
$$

where $\mathrm{m}_{1}$ and $\mathrm{m}_{2}$ are weight before and after immersion $(\mathrm{mg}), \mathrm{A}$ is surface area $\left(\mathrm{cm}^{2}\right)$ of mild steel, $\mathrm{t}$ is immersion time (hours), $\mathrm{CR}_{1}$ and $\mathrm{CR}_{2}$ are corrosion rate without and after the addition of inhibitors ( $\mathrm{mg}$ $\left.\mathrm{cm}^{-2} \mathrm{~h}^{-1}\right) .{ }^{18-19}$

\section{Potentiodynamic Polarization Method}

Potentiodynamic polarization measurements were carried out using the eDAQ 466 potentiostat. The conventional three-electrode system was used for these measurements. Mild steel specimens were used as the working electrode with a surface area of $0.0214 \mathrm{~cm}^{2}$. Pt and $\mathrm{Ag} \mid \mathrm{AgCl}$ electrodes were used as auxiliary and reference electrodes. Potentiodynamic polarization measurements were carried out in $1 \mathrm{M}$ $\mathrm{HCl}$ with different concentrations of MOSE. The three electrodes were immersed in a vessel containing a corrosive medium without and in the presence of an inhibitor. All the electrochemical studies were carried out at room temperature. The potential was measured to obtain the curve of the relationship between the potential $(\mathrm{mV})$ to $\ln$ of current $\left(\mathrm{mA} / \mathrm{cm}^{2}\right)$.

\section{FTIR Measurements}

FTIR measurement was carried out by taking concentrated extracts or MOSE and then was attached to the mild steel before analyzed by FTIR instrument. The FTIR spectrum of MOSE was recorded by Fourier transforms infrared spectrophotometer (Nicolet IS10 FT-IR, Thermo Scientific). 
RASĀYAN J. Chem.

Vol. 13 | No. 1 |230 - 239| January - March | 2020

\section{SEM Analysis}

Mild steel coupon was immersed in medium $1 \mathrm{M}$ hydrochloric acid without and with the presence of MOSE for 6 days. After that, the mild steel was dried and analyzed by SEM instrument.

\section{Phytochemical Test}

\section{RESULTS AND DISCUSSION}

The extraction of Mangifera odorata Griff seeds with methanol produces thick green dark extracts. Phytochemical testing was conducted in order to identify the component of secondary metabolite compounds contained in MOSE. The results of the test are shown in Table-1. The phytochemical analysis showed that the extract contains the compound groups, i.e., flavonoids, phenolic, and steroids while saponins, triterpenoid, and alkaloids, were not present. This seed extract contained some secondary metabolites can function as a corrosion inhibitor.

Table-1: Results of Phytochemical Test of MOSE (+: present, -: absence)

\begin{tabular}{c|c}
\hline Compound & Result \\
\hline Flavonoids & + \\
\hline Phenolic & + \\
\hline Steroids & + \\
\hline Saponin & - \\
\hline Triterpenoid & - \\
\hline Alkaloids & -
\end{tabular}

\section{FTIR Analysis}

It is well known that the potential compounds that can act as a corrosion inhibitor are the compounds with a functional group of hydroxyls $(-\mathrm{OH})$, carboxyl $(-\mathrm{COOH})$, carbonyl $(=\mathrm{CO}),-\mathrm{CO}-$, amine $(-\mathrm{C}=\mathrm{N})$ and other functions that have electrons pair. ${ }^{20-21}$ The FTIR spectrum of MOSE is shown in Fig.-1(a). The original absorption band at $3251.21 \mathrm{~cm}^{-1}$ is the wavenumbers of $-\mathrm{OH}$ group (alcohol), and at $1702.73 \mathrm{~cm}$ ${ }^{1}$ is the wavenumber of $-\mathrm{C}=\mathrm{O}$ group in a compound. This infrared spectrum shows the chemical content in MOSE which is potential as a corrosion inhibitor that can bond directly to form a stable complex. The complexes formed in the corrosive medium $1 \mathrm{M} \mathrm{HCl}$ will be adsorbed on the surface of mild steel.

Figure-1(b) shows the FTIR spectrum of layers that were formed on the mild steel surface after immersed in $1 \mathrm{M} \mathrm{HCl}$ and added by MOSE. From this spectrum observed that the $-\mathrm{OH}$ stretch was shifted from $3251.21 \mathrm{~cm}^{-1}$ to $3300.28 \mathrm{~cm}^{-1}$ and the transition frequency of the $-\mathrm{CO}-$ group from $1693.02 \mathrm{~cm}^{-1}$ to $1624.67 \mathrm{~cm}^{-1}$. The shift or change of FTIR spectrum of layers on mild steel surfaces or corrosion products is different from the spectrum obtained for the methanol extract of Mangifera odorata Griff seed (phenolic, flavonoid, and steroid), and this indicates the interaction occurred between extract and the mild steel surface. It can be said that the extract has a protective effect and can inhibit the corrosion rate of mild steel.

\section{Weight Loss Analysis}

The corrosion rate for mild steel in $1 \mathrm{M} \mathrm{HCl}$ solution at $30,40,50$, and $60^{\circ} \mathrm{C}$ in the absence and presence of MOSE are given in Fig.-2. Increasing the concentration of MOSE in a corrosive medium cause a decrease in the corrosion rate of mild steel. At $30^{\circ} \mathrm{C}$ in the absence of MOSE, the corrosion rate reaches $0.59 \mathrm{mg} / \mathrm{cm}^{2} \mathrm{~h}$, but in the presence of $8 \mathrm{~g} / \mathrm{L}$ MOSE in the medium causes the corrosion rate drop to 0.04 $\mathrm{mg} / \mathrm{cm}^{2} \mathrm{~h}$. Decreasing of the corrosion rate indicates that MOSE has been adsorbed on the mild steel surface. This absorbed substances will become a barrier that separates the mild steel surface from the corrosive medium.

Figure-2 shows the corrosion rate value of mild steel increases with the rise of immersion temperature or corrosive medium temperature. This occurred because the rise of temperature can increase the kinetic energy of corrosion-causing particles in a corrosive medium. In the exothermic process, high particle kinetic energy will increase the collisions between particles and surface of the mild steel so that the rust growing on the surface will increase. An increase in temperature will cause the inhibition efficiency value decreased because at high temperatures the desorption process of inhibitors that have been adsorbed on the mild steel surface occurred. Thus, the ability to extract to act as an inhibitor will be reduced. ${ }^{20,22}$ 
RASĀYAN J. Chem.

Vol. 13 | No. 1 |230 - 239| January - March | 2020
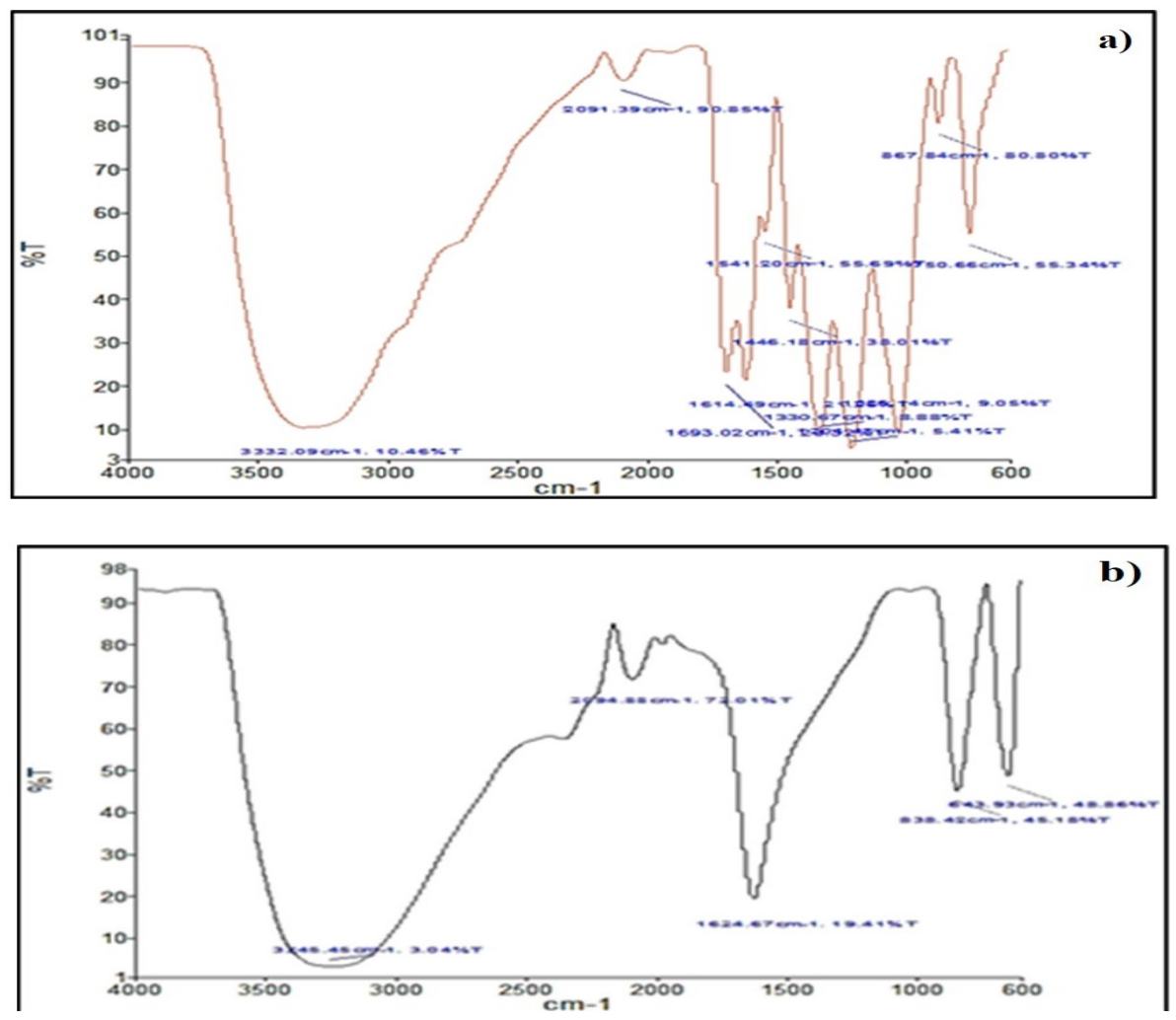

Fig.-1: FTIR Spectra of (a) Mangifera odorata Griff Seed Extract (b) Corrosion Layer of Mild Steel After Immersion in $1 \mathrm{M} \mathrm{HCl}$ in the Presence of MOSE.

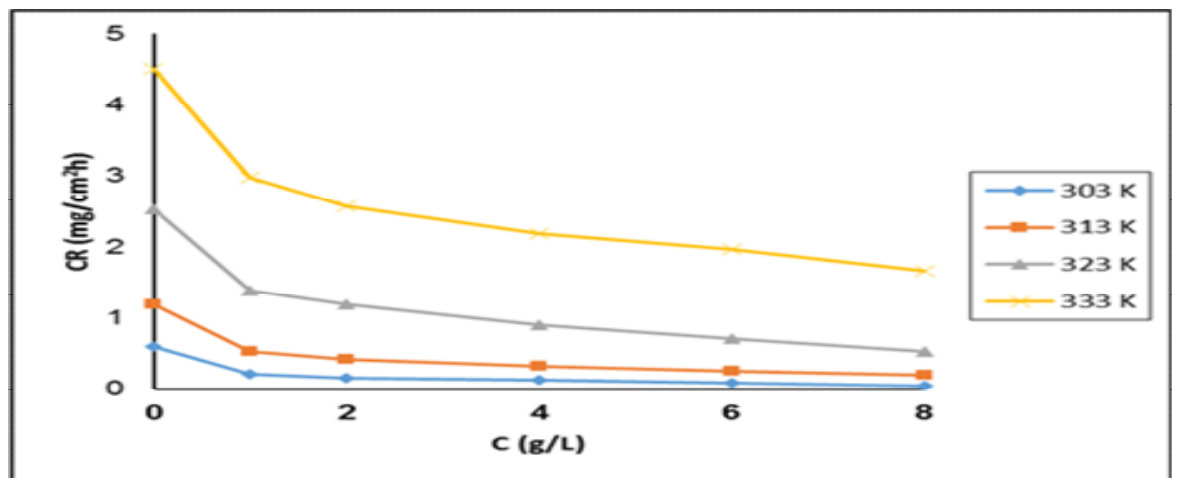

Fig.-2: The influence of MOSE Concentration on Mild Steel Corrosion Rate In 1M HCl Medium Without and with the Addition of the Inhibitors.

The adsorption occurred on the mild steel surface shows a significant relationship between the inhibitory efficiency of corrosive media without and with the addition of inhibitors indicate the ability of inhibitors inhibiting corrosion. MOSE provides a significant corrosion inhibitory effect on mild steel in $1 \mathrm{M} \mathrm{HCl}$ solution, which reaches up to $94.55 \%$ at a concentration of $8 \mathrm{~g} / \mathrm{L}$ MOSE.

Improvements in efficiency are shown in Fig.-3. The interactions between compounds in Mangifera odorata Griff seed extract and the mild steel surfaces that occur through the adsorption mechanism will form a thin layer on the mild steel surface. With the increase of adsorption capacity, the mild steel will be further protected from corrosion attacks, and the inhibition efficiency value will also increase. The inhibition efficiency value decreases with the increasing temperature of the corrosive medium. The reduction in inhibition efficiency is due to desorption of MOSE from the mild steel surface (Fig.-3). ${ }^{23}$ 
RASĀYAN J. Chem.

Vol. 13 | No. 1 |230 - 239| January - March | 2020

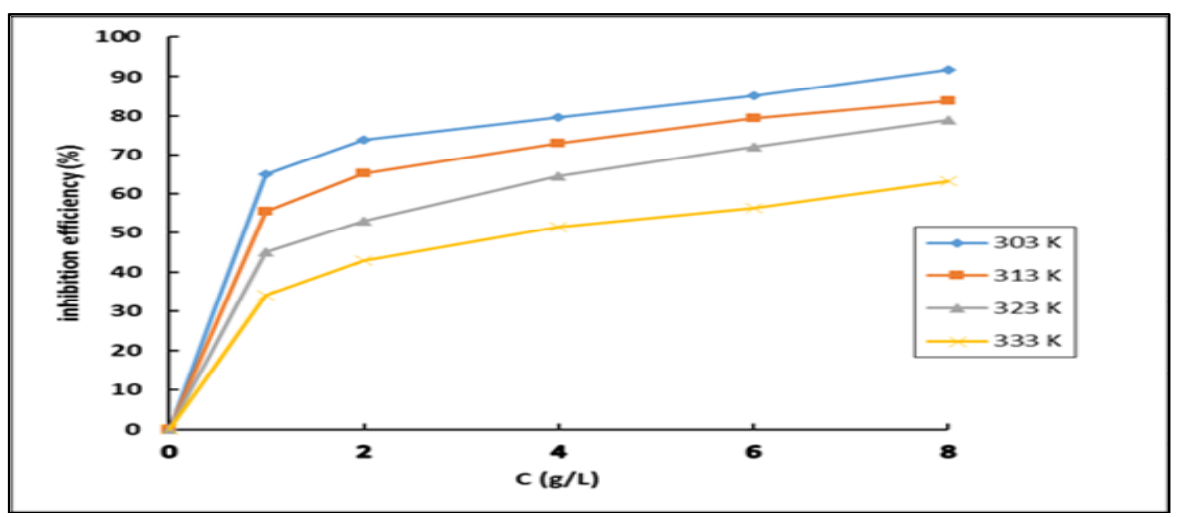

Fig.-3: The effect of MOSE Concentration on Corrosion Inhibition Efficiency of Mild Steel in 1M HCl Solution in the Presence and Absence of Inhibitors.

\section{Thermodynamic Considerations}

The corrosion rate value determined from the weight loss measurements were acclimated to evaluate the apparent activation energy $\left(E_{a}\right)$ for mild steel corrosion in $1 \mathrm{M} \mathrm{HCl}$ solution in the absence and presence of MOSE at 303-333 K using Arrhenius equation (3). ${ }^{8-11}$

$$
C R=A \exp \left(-\frac{E_{a}}{R T}\right)
$$

Where $A$ is the pre-exponential factor, $E_{a}$ is activation energy $\left(\mathrm{kJmol}^{-1}\right), R$ is the molar gas constant $(8.314$ $\left.\mathrm{Jmol}^{-1}\right), T$ is the temperature (K). The plots of $\ln C R$ versus $1 / T$ without and with inhibitor gave straight lines (Fig.-4). The values of $E_{a}$ calculated from the slopes of the straight lines are listed in Table-2. The higher values of activation energy in the presence of MOSE is an agreement with a decrease in corrosion inhibition efficiency, and the increase of temperature suggests the physisorption between the mild steel surface and MOSE.

Adsorption of inhibitors decreased on the surface of mild steel with an increase in temperature. The increase in temperature causes an increase in the reaction rate of mild steel surfaces that interact with hydrochloric acid also increase. The value of enthalpy $\left(\Delta H^{*}\right)$ and entropy $\left(\Delta S^{*}\right)$ of activation of the corrosion process were calculated using the alternative Arrhenius equation:

$$
C R=\frac{R T}{N h} \exp \left(\frac{\Delta S^{*}}{R}\right) \exp \left(-\frac{\Delta H^{*}}{R T}\right)
$$

$N$ is Avogadro constant $\left(6.023 \times 10^{23}\right.$ molecules $\left.\mathrm{mol}^{-1}\right), h$ is Planck's constant $\left(6.63 \times 10^{-34} \mathrm{Js}^{-1}\right), \Delta H^{*}$ is the enthalpy of activation $\left(\mathrm{kJmol}^{-1}\right)$, and $\Delta S^{*}$ is the entropy of activation $\left.\left(\mathrm{Jmol}^{-1}\right)\right)^{22-25}$

The thermodynamic parameter values of $\Delta H^{*}$ and $\Delta S^{*}$ were obtained through the interception calculation of the Arrhenius equation and its alternative equation (Fig.-5). The results show that with the increase in temperature, there is a decrease in the value of IE due to the corrosion that will be easier to occur at high temperatures. If there is MOSE in the corrosive medium, the corrosion activation energy will be higher than without MOSE in solution. The results obtained showed that MOSE functioned as an inhibitor by increasing the activation energy of mild steel dissolution by forming a barrier layer on the surface. ${ }^{8}$

The value of $\Delta H^{*}$ and $\Delta S^{*}$ from the mild steel immersion process in $1 \mathrm{M} \mathrm{HCl}$ solution was found to be higher if presence MOSE in the medium rather than without MOSE. The positive $\Delta H^{*}$ value indicates the process of dissolving mild steel in the corrosive medium is endothermic and requires higher energy to achieve equilibrium. Whereas the negative $\Delta S^{*}$ value is good if there are MOSE or without MOSE in $1 \mathrm{M}$ $\mathrm{HCl}$ solution. This shows that the process of association of activated complexes is easier than the dissociation.

\section{Determination of Isotherm Adsorption}

The calculation of thermodynamic parameter values is intended to gain an understanding of the electrochemical process on the mild steel surface and the adsorption characteristics. This process is related to the adsorption of inhibitor molecules and the adsorption depends on the chemical structure. 
RASĀYAN J. Chem.

Vol. 13 | No. 1 |230 - 239| January - March | 2020

Isotherm adsorption is a very important factor in determining the electrochemical reaction mechanism of organic compounds, both natural and synthetic compounds. Several adsorption isotherms can be used to determine the adsorption behavior of the inhibitors. However, the most commonly used are Langmuir, Temkin and Freundlich adsorption isotherm. ${ }^{10,16,23}$

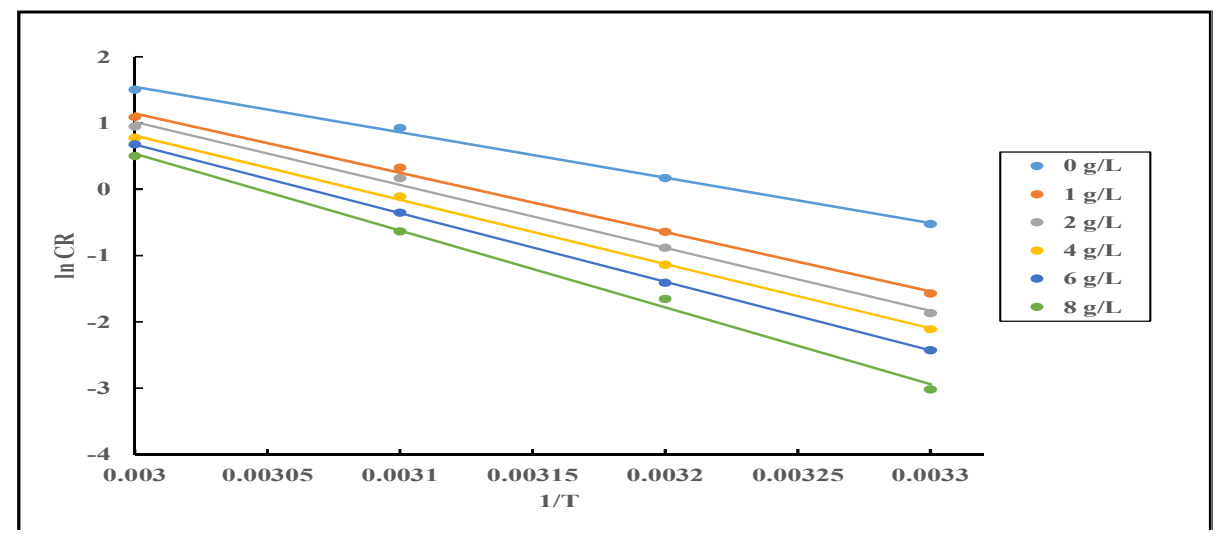

Fig.-4: Arrhenius Plots of Mild Steel in 1M HCl and 1M HCl Added MOSE

Table-2: The Value of Activation Energy, Enthalpy, and Entropy of Mild Steel Corrosion in 1M HCl Without and in the Present of MOSE

\begin{tabular}{c|c|c|c}
\hline $\mathrm{C}(\mathrm{g} / \mathrm{L})$ & $\begin{array}{c}\text { Activation Energy } \\
(\mathrm{kJ} / \mathrm{mol})\end{array}$ & $\Delta H^{*}(\mathrm{~kJ} / \mathrm{mol})$ & $\Delta S^{*}(\mathrm{~J} / \mathrm{mol})$ \\
\hline 0 & 56.87 & 54.23 & -70.21 \\
\hline 1 & 74.41 & 71.79 & -20.92 \\
\hline 2 & 78.95 & 76.34 & -8.37 \\
\hline 4 & 80.64 & 78.02 & -5.01 \\
\hline 6 & 86.17 & 83.56 & 10.47 \\
\hline 8 & 96.43 & 93.82 & 40.11 \\
\hline
\end{tabular}

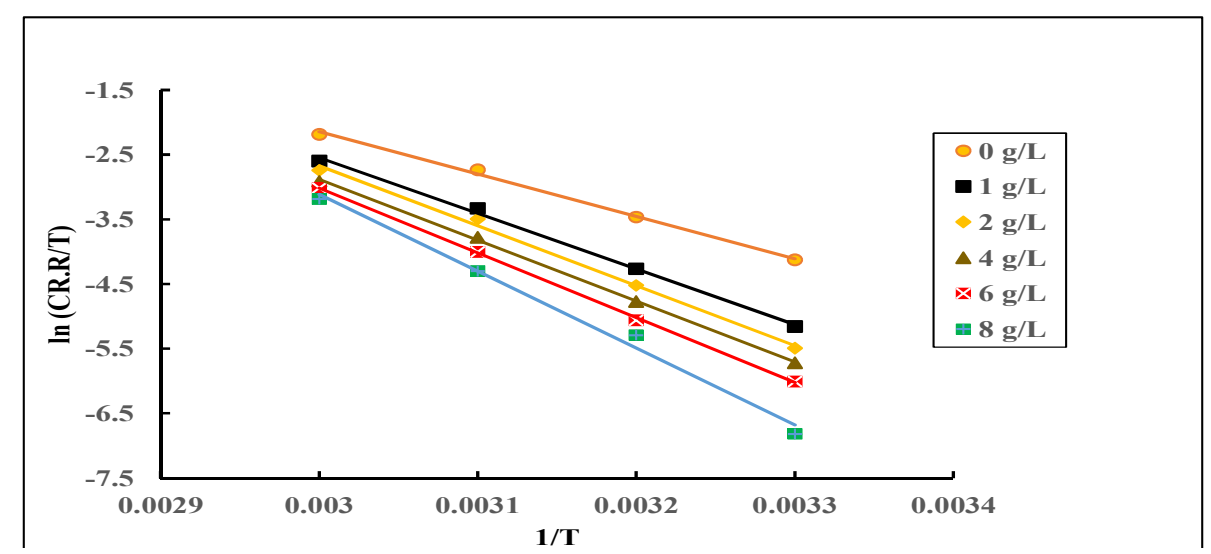

Fig.-5: Plots of Transition State $\ln C R / T$ Versus $1 / T$ at Different Concentrations of MOSE in $1 \mathrm{M} \mathrm{HCl} \mathrm{Solution}$

Increasing the value of the activation energy and enthalpy when the addition of the extract to the corrosive medium was due to the extract has been adsorbed on the mild steel surface. The positive $\Delta H^{*}$ values indicate that the interaction of active species with mild steel surfaces during the immersion process is endothermic. ${ }^{10,27}$

The study of adsorption isotherm was calculated using the Langmuir and Freundlich isotherm equations. Corrosion inhibition of mild steel using the MOSE inhibitor follows the Langmuir isotherm adsorption pattern with the determination coefficient $\left(\mathrm{R}^{2}\right)$ obtained close to 1 (Fig.-6). 
RASĀYAN J. Chem.

Vol. 13 | No. 1 |230 - 239| January - March | 2020

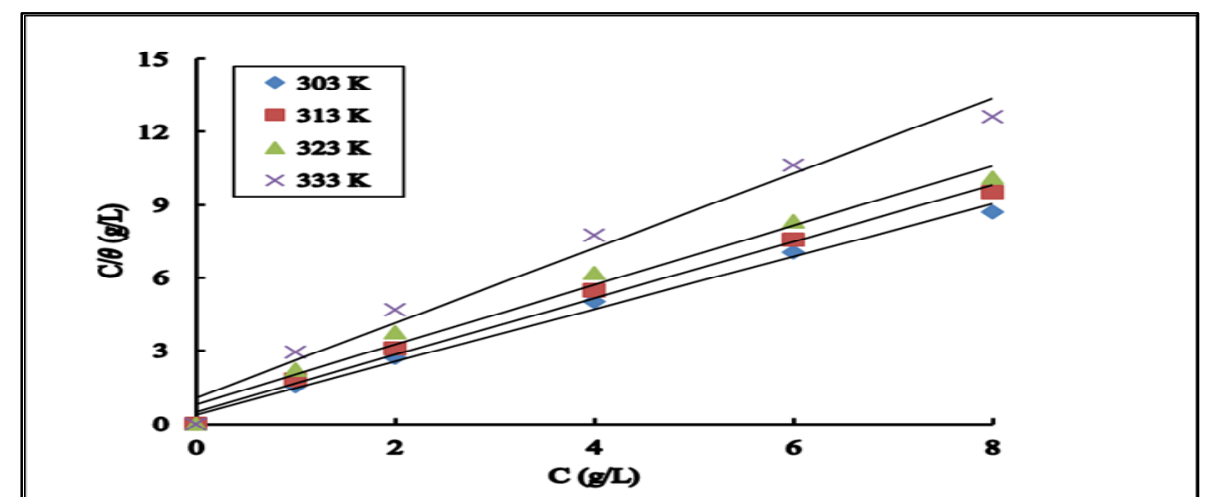

Fig.-6: The Langmuir Adsorption Plot of Mild Steel in 1M HCl Containing Various Concentrations of MOSE at Different Temperatures

Furthermore, adsorption of inhibitors molecular from the corrosive medium to the surface of mild steel is a substitution process. The correlation between surface coverage $(\theta)$ is defined by $\%$ IE/100 and the concentration of inhibitor $\left(C_{i n h}\right)$ in the hydrochloric acid solution can be represented by the equation:

$$
\frac{C_{i n h}}{\theta}=\frac{1}{K_{a d s}}+C_{i n h}
$$

Where $C_{i n h}$ is the inhibitor concentration, $\theta$ is the surface coverage and $K_{a d s}$ is the adsorption equilibrium constant. The plot of $C_{i n h} / \theta$ against $C_{i n h}$ yielded straight lines is shown in Fig.-6. This is because the adsorption of inhibitor molecules on the mild steel surface that matches the Langmuir adsorption isotherm and the coefficient of determination between surface coverage and the concentration of MOSE obtained are all close to 1 . The surface coverage values itself is obtained from the MOSE were obtained from measurements of weight loss for various concentrations of MOSE in 1M hydrochloric acid solution at different temperatures $(303-333 \mathrm{~K})$.

The basic of Van't Hoff equation can be used to calculate the standard adsorption enthalpy $\left(\Delta H^{o}{ }_{a d s}\right)$, and for that, it can also be re-arranged as the following equation:

$$
\ln K_{a d s}=\left(-\Delta H_{a d s}^{o}\right) / R T
$$

The adsorptive equilibrium constant $\left(K_{a d s}\right)$ relating to the standard adsorption free energy $\left(\Delta G_{a d s}^{o}\right)$ obtained according to:

$$
\Delta G_{a d s}^{o}=-R T \ln \left(999 \times K_{a d s}\right)
$$

Both parameters of $\Delta G^{o}{ }_{a d s}$ and $\Delta H^{o}{ }_{a d s}$, was used to obtain the standard adsorption entropy ( $\Delta S^{o}{ }_{a d s}$ ) using the following thermodynamic basic equation:

$$
\Delta S_{a d s}^{o}=\left(-\Delta H_{a d s}^{o}-\Delta G_{a d s}^{o}\right) / T
$$

Where $\Delta G_{a d s}^{o}$ is the free energy Gibbs, $K_{a d s}$ is the adsorption constant, $C_{i n h}$ is the inhibitor concentration, $\Delta S^{o}{ }_{a d s}$ is the standard entropy of adsorption, and $\Delta H^{o}{ }_{a d s}$ is the standard enthalpy of adsorption. ${ }^{11,26}$

All calculations result of thermodynamic parameters is listed in Table-3. The higher value of $K_{a d s}$ indicates that the extract adsorbed well on the mild steel surface. The negative value of $\Delta G_{\text {ads }}^{o}$ indicates that the adsorption of MOSE on the mild steel surface occurred spontaneously. While the low value of $\Delta H^{o}{ }_{a d s}$ also shows that the adsorption occurred is physical adsorption. ${ }^{27}$ The negative value of $\Delta S^{o}{ }_{a d s}$ shows that the MOSE adsorption process on a mild steel surface was accompanied by a decrease in the entropy value. It proves that the adsorption inhibitor is accompanied by the desorption of water molecules which are less than the surface of the steel. Before adsorption took place on the steel surface, the level of 
RASĀYAN J. Chem.

Vol. 13 | No. 1 |230 - 239| January - March | 2020

the irregularity of inhibitor molecules is high, but when the inhibitor molecule was adsorbed onto the steel surface, it occurs regularly which results in a decrease in the adsorption entropy. ${ }^{10,27-31}$

Table-3: Langmuir Adsorption and Thermodynamic Parameters of Adsorption of MOSE as Corrosion Inhibitor on

\begin{tabular}{c|c|c|c|c|c}
\multicolumn{7}{c}{ the Surface of Mild Steel } \\
\cline { 1 - 4 } Temp. (K) & $K_{a d s}$ & $\mathrm{R}^{2}$ & $\begin{array}{c}\Delta G^{o}{ }_{a d s} \\
(\mathrm{~kJ} / \mathrm{mol})\end{array}$ & $\begin{array}{c}\Delta H^{o}{ }_{a d s} \\
(\mathrm{~kJ} / \mathrm{mol})\end{array}$ & $\begin{array}{c}\Delta S^{o}{ }_{a d s} \\
(\mathrm{~J} / \mathrm{mol})\end{array}$ \\
\hline 303 & 2.62 & 0,9926 & -19.83 & -30.01 & -33.28 \\
\hline 313 & 2.04 & 0,9921 & -19.83 & & \\
\cline { 1 - 3 } 323 & 1.23 & 0,9801 & -19.11 & & \\
\hline 333 & 0.94 & 0,9785 & -18.95 & & \\
\hline
\end{tabular}

\section{Measurement of Polarization Potensiodinamik}

Potentiodynamic polarization methods are used to determine the corrosion properties of metals based on potential and anodic or cathodic current relationships. Potentiodynamic polarization plots of anodic and cathodic mild steel poles in $1 \mathrm{M} \mathrm{HCl}$ solution in the absence and presence of different MOSE concentrations as shown in Fig.-7. The corrosion current can then be converted to a corrosion rate. The potentiostat is a device used in electrochemical research to observe the ongoing corrosion process. ${ }^{11,32}$

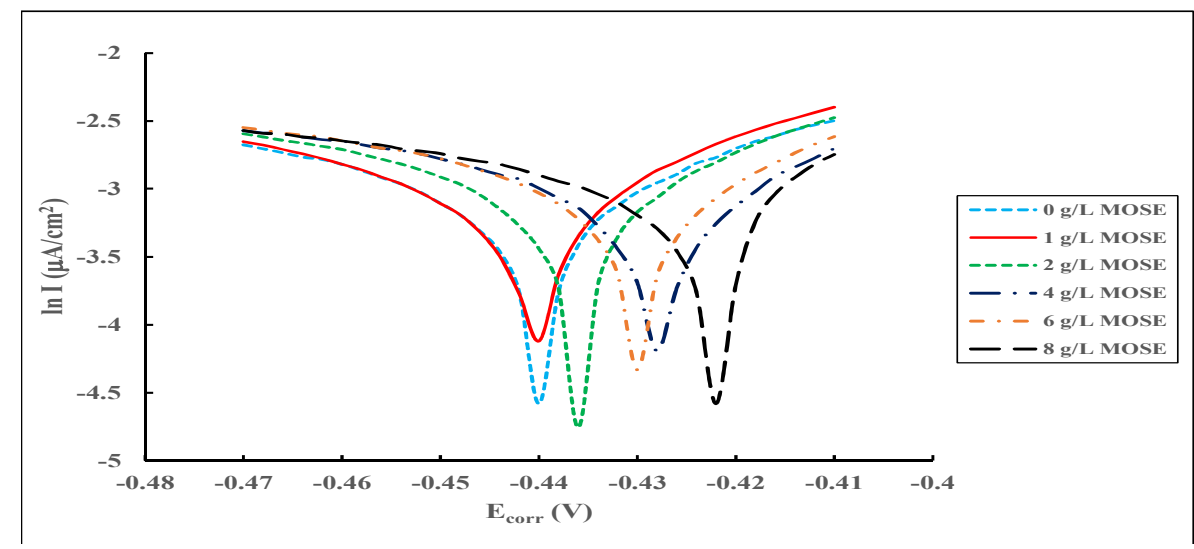

Fig.-7: The Potentiodynamic Polarization Curve without and with the Addition of the MOSE in the HCl Medium

In Fig.-7, the potentiodynamic polarization curve is revealed in the absence of MOSE in a corrosive medium. The curve is located on the left of the lowest $\mathrm{E}_{\text {corr }}-0.446 \mathrm{~V}$. The relatively lower value shows the corrosion potential of hydrochloric acid is more negative than the potential value of corrosion inhibitor. The corrosive potential will be higher if in the corrosive medium the concentration of the extract increases. The displacement of $\mathrm{E}_{\text {corr }}$ is $<85 \mathrm{mV}$ (Table-4), indicating that MOSE inhibitors can act as mixed-type inhibitors. It also shows these inhibitors can block the reaction on mild steel surfaces and change the metal dissolution mechanism and hydrogen evolution reaction. The relationship between the concentration of MOSE and current and potential and the inhibition efficiency are given in Table- 4 .

The corrosion potential $\left(\mathrm{E}_{\text {corr }}\right)$ of mild steel in medium without extract is more negative than the addition of MOSE. Corrosion current $\left(\mathrm{I}_{\text {corr }}\right)$ values decrease with increasing MOSE concentration in medium $1 \mathrm{M}$ $\mathrm{HCl}$. The inhibition efficiency values also increase with increasing MOSE concentration in solution. This result indicates that the weight loss method and the potentiodynamic polarization method show the same results, namely the efficiency of inhibiting corrosion of steel increases with increasing concentration of MOSE.

\section{SEM Analysis}

Micrograph of scanning electron microscopy provides the information about the morphology of untreated mild steel, immersed in a solution of $1 \mathrm{M} \mathrm{HCl}$ and in $1 \mathrm{M} \mathrm{HCl}$ with the addition of the MOSE. 
RASĀYAN J. Chem.

Vol. 13 | No. 1 | 230 - 239| January - March | 2020

Table-4: Changes in Potential, Current and Efficiency of Inhibition with MOSE in the HCl Medium
\begin{tabular}{c|c|c|c}
\hline $\begin{array}{c}\text { The concentration } \\
\text { of MOSE }(\mathrm{g} / \mathrm{L})\end{array}$ & $\mathrm{E}_{\text {corr }}(\mathrm{V})$ & $\ln \mathrm{I}\left(\mathrm{mA} / \mathrm{cm}^{2}\right)$ & Inhibition Efficiency(\%) \\
\hline 0 & -0.446 & 0.0110 & 0 \\
\hline 1 & -0.438 & 0.0050 & 54.55 \\
\hline 2 & -0.436 & 0.0037 & 66.36 \\
\hline 4 & -0.428 & 0.0014 & 87.27 \\
\hline 6 & -0.436 & 0.0013 & 94.55 \\
\hline 8 & -0.422 & 0.0006 & \\
\hline
\end{tabular}

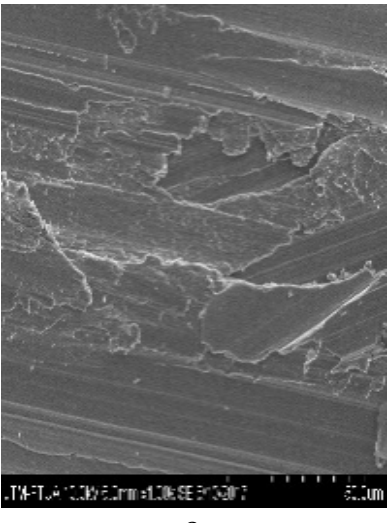

a

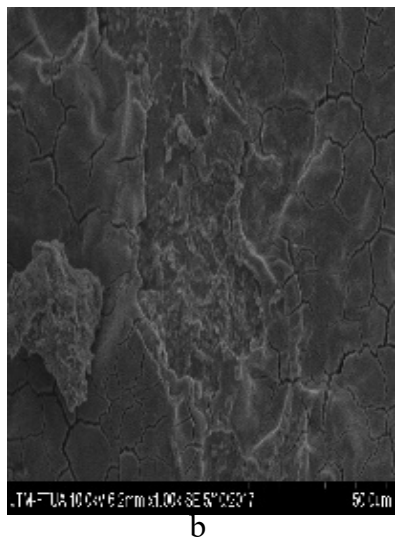

b

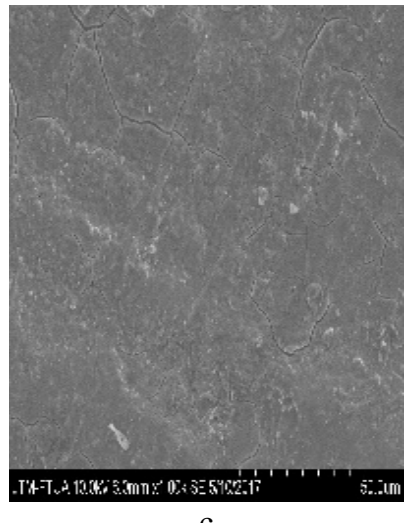

C

Fig.-8: SEM Image of Mild Steel Surface with a Magnification of 1000x (a) Without Treatment, (b) in Solution of $1 \mathrm{M} \mathrm{HCl}$, and (c) in Solution of $1 \mathrm{M} \mathrm{HCl}+8 \mathrm{~g} / \mathrm{L}$ of MOSE

Figure-8a observed that the mild steel surface is smooth and fairly flat, not porous and corrosion-free. Fig. $-8 \mathrm{~b}$ is a steel surface after immersed in $1 \mathrm{M} \mathrm{HCl}$ reveals that the surface is very rusty due to the absence of an inhibitor because of the aggressive acid attack ${ }^{30}$. While Fig.-8c shows the surface conditions of steel specimens are much better and smoother than those soaked in $1 \mathrm{M} \mathrm{HCl}$ solution. The decrease in corrosion rates occurred because MOSE was adsorbed on the steel surface. So it can be concluded that MOSE can inhibit mild steel corrosion in the $1 \mathrm{M} \mathrm{HCl}$ solution.

\section{CONCLUSION}

Mangifera odorata Griff seed extract is a potential and effective natural compound used as a corrosion inhibitor. The value of the highest inhibition efficiency of $91.78 \%$ was obtained by weight loss and $94.55 \%$ by potentiodynamic polarization method at MOSE concentration of $8 \mathrm{~g} / \mathrm{L}$ and the immersion temperature of $30^{\circ} \mathrm{C}$. The result of potentiodynamic polarization measurements indicates that MOSE is a mixed type inhibitor.

\section{ACKNOWLEDGMENT}

All authors acknowledge the financial support from FMIPA Universitas Andalas for Fundamental Research contract no. 01/UN16.03.D/PP/FMIPA/2017 Financial Year 2017.

\section{REFERENCES}

1. A. Ehsani, M.G. Mahjani, M. Hosseini, R. Safari, R. Moshrefi, and H.M. Shiri, Journal of Colloid and Interface Science, 490, 444 (2017), DOI: 10.1016/j.jcis.2016.11.048

2. G.M. Al-Senani, International Journal of Electrochemical Science, 11, 291 (2016)

3. H. Lgaz, R. Salghi, and H.A. Ismat, International Journal of Electrochemical Science, 13, 250 (2018), DOI: $10.2964 / 2018.01 .26$

4. N. M'hiri, D. Veys-Renaux, E. Rocca, I. Ioannou, N.M. Boudhrioua, and M. Ghoul, Corrosion Science, 102, 55 (2016), DOI:10.1016/j.corsci.2015.09.017

5. S.A. Umoren, I.B. Obot, A.U. Israel, P.O. Asuquo, M.M. Solomon, U.M. Eduok, and A.P. Udoh, Journal of Industrial and Engineering Chemistry, 20, 3612 (2014), DOI:10.1016/j.jiec.2013.12.056 
RASĀYAN J. Chem.

Vol. 13 | No. 1 |230 - 239| January - March | 2020

6. M. Chellouli, D. Chebabe, A. Dermaj, H. Erramli, N. Bettach, N. Hajjajia, M.P. Casaletto, C. Cirrincione, A. Priviterab, and A. Srhiri, Electrochimica Acta, 204, 50(2016), DOI:10.1016/j.electacta.2016.04.015

7. E.E. Oguzie, Corrosion Science, 50, 2993 (2008), DOI:10.1016/j.corsci.2008.08.004

8. S. Muthumanickam, B. Jeyaprabha, R. Karthik, A. Elangovan, and P. Prakash, International Journal of Corrosion Scale Inhibition, 4, 365 (2015), DOI:10.17675/2305-6894-2015-4-4-6

9. Y. Guo, M. Gao, H. Wang, and Z. Liu, International Journal of Electrochemical Science, 12, 140 (2017), DOI: 10.20964/2017.02.25

10. Emriadi, A. Santoni, and Y. Stiadi, Der Farma Chemica, 8, 266 (2016)

11. A. Ostovari, S.M. Hoseinieh, M. Peikari, S.R. Shadizadeh, and S.J. Hashemi, Corrosion Science, 51, 1935 (2009), DOI:10.1016/j.corsci.2009.05.024

12. O.K. Abiola and A.O. James, Corrosion Science, 52, 661 (2010), DOI:10.1016/j.corsci.2009.10.026

13. S.K. Hasan and P. Sisodia, Rasayan Journal Chemistry, 4, 548 (2011)

14. A. Mathina and R. Rajalakshmi, Rasayan Journal Chemistry, 9, 56, (2016)

15. N.K. Ketis and B. Bundjali, Jurnal Matematika dan Sains, 15, 43 (2010)

16. C. Kamal and M.G. Sethuraman, Arabian Journal of Chemistry, 5, 155 (2012), DOI: 10.1016/j.arabjc.2010.08.006

17. J.B. Harbone, Phytochemical method-a guide to modern technique of plant analysis 2nd ed., Chapman and Hall, New York, p. 48, 49, 63, 64, 129, 132 (1998)

18. M.A. Amin, S.S. El-Rehim, E.E.F. El-Sherbini, and R.S. Bayoumi, Electrochimica Acta, 52, 3588 (2007), DOI: 10.1016/j.electacta.2006.10.019

19. S. Deng and X. Li, Corrosion Science, 55, 407 (2012), DOI:10.1016/j.corsci.2011.11.005

20. A. Saxena, D. Prasad, R. Haldhar, G. Singh and A. Kumar, Journal of Molecular Liquids, 258, 89 (2018), DOI:10.1016/j.molliq.2018.02.104

21. P. Muthukrishnan, B. Jeyaprabha, and P. Prakash, Arabian Journal of Chemistry, 10, S2343 (2017), DOI: $10.1016 /$ j.arabjc. 2013.08 .011

22. H.E. Gadow and H.M. Elabbasy, International Journal of Electrochemical Science, 12, 5867 (2017), DOI: $10.20964 / 2017.07 .13$

23. N. Soltani, N. Tavakkoli, M.K. Kashani, A. Mosavizadeh, E.E. Oguzie, and M.R. Jalali, Journal of Industrial and Engineering Chemistry, 20, 3217 (2014), DOI:10.1016/j.jiec.2013.12.002

24. P. Mourya, S. Banarjee, and M. Singh, Corrosion Science, 85, 352 (2014), DOI: 10.1016/j.corsci.2014.04.036

25. T.A. Salman and A.B. Mohammed, Rasayan Journal Chemistry, 10, 815 (2017), DOI: 10.7324/RJC.2017.1031751

26. M. Gopiraman, N. Selvakumaran, D. Kesavan, and R. Karvembu, Progress in Organic Coatings, 73, 104 (2012), DOI: 10.1016/j.porgcoat.2011.09.006

27. J. Bhawsar, P.K. Jain, and P. Jain, Alexandria Engineering Journal, 54, 769 (2015), DOI: 10.1016/j.aej.2015.03.022

28. K. Zakaria, A. Hamdy, M.A. Abbas, and O.M. Abo-Elenien, Journal of The Taiwan Institute of Chemical Engineers, 65, 530 (2016), DOI:10.1016/j.jtice.2016.05.036

29. N.A. Odewunmi, S.A Umoren, and Z.M. Gasem, Journal of Industrial and Engineering Chemistry, 21, 239 (2015), DOI:10.1016/j.jiec.2014.02.030

30. L.Y.S. Helen, A.A. Rahim, B. Saad, M.I. Saleh, and P.B. Raja, International Journal of Electrochemical Science, 9, 830 (2014)

31. K. Boumhara, M. Tabyaoui, C. Jama, and F. Bentiss, Journal of Industrial and Engineering Chemistry, 29, 146 (2015), DOI:10.1016/j.jiec.2015.03.028

32. M. Faustin, A. Maciuk, P.A. Salvin, C. Roos, and M. Lebrini, Corrosion Science, 92, 287 (2015), DOI:10.1016/j.corsci.2014.12.005

[RJC-5325/2019] 